\title{
Deconstructing Walt Disney's The Lion King
}

\author{
By Vicky Wong \\ Spring 1999 Issue of KINEMA
}

\section{DECONSTRUCTING THE WALT DISNEY ANIMATION THE LION KING: ITS IDEOL- OGY AND THE PERSPECTIVE OF HONG KONG CHINESE}

Walt Disney's animations have always been popular, largely of course due to their aesthetic appeal, vivid characters, interesting plots, and for the parents, obvious moral standards that save their time teaching their children.

The artifact this paper is going to study is one of Disney's most popular animation The Lion King released in 1994 both in the US and in Hong Kong. The film broke all records in the first weekend, grossing USD42 million. It was similarly popular when it was released in Hong Kong during the summer vacation in the same year. Simply put, the story is about how a regal lion is victimised by his uncle: experiences an exile and a life free from responsibility: free by whim or by chance, when he grows up, meets up with his friend and goes through a period of identity crisis and introspection: and finally, the lion gains back his throne by challenging the illegitimate king, his uncle.

Though in the form of an animation which one would naturally think is dedicated to children, and which is generally thought of as being surrealistic, which at most contain moral lessons. The Lion King, in analysis, is more than a fable. I will argue that The Lion King should "rightfully" (a term often appears in the script as we will discuss later) be an adult's film. Hinson (1994) said, "Of the 32 animated films Disney has produced, this story of a young African lion's search for identity is not only more mature in its themes, it is also the darkest and the most intense. Shakespearean in tone, epic in scope, it seems more appropriate for grown-ups than for kids." Ebert (1994) also expressed that the superbly drawn animated feature was surprisingly solemn in its subject matter and was too intense for small children. And actually the violence depicted and the death illustrated are always commented as too much for the children.

The animation is not a mere light entertainment either. It is not just one that depicts the lovely cub's life cycle, nor is it true in describing the real life of the animals. As Neufeld (1996) said, the characters in The Lion King exhibit behaviours that are uncharacteristic of animals they portray. First, the mix of the animal kingdom is just a dream. Who will think of all the antelopes, elephants, leopards, lions, etc living peacefully together? And the caring relationship between the mother lions and the cubs, and between the lions and lionesses cannot really be seen in real life, where the non-father males will kill other male's offspring and cubs are always abundant and dying of starvation. The relationship, and hence the struggle, depicted is more human in nature.

Apart from the moral lessons said to be inculcated in children, as many other animations do, a number of themes emphasised by different critics abound in The Lion King (e.g. social interactions, familial relations, bravery, responsibility, vulnerability, faith etc. See Schwalm, 1995; and The Lion King -- Production Information, 1994). This paper will, however, probe into the theme of "hegemony," both in the senses of power and male dominance, as well as the perspective of Hong Kong Chinese people in this regard, arising out of the fact that the animation has been so popular when it was released.

\section{Here Comes the Hero, Simba}

In this section, we will study the text in question using Jungian's concept of "archetype". According to Jung, archetype refers to a universal image or theme found in dreams, myths, religions, philosophies, and works of art. It exists beyond the realm of the personal unconscious found in all people (Berger, 1993). The archetype under study will be the "hero" archetype, which as observed, should be of note since:

- it resembles the Chinese archetypes; and

- it reinforces the existing hegemony

\section{The Structure}

The original script of the text contains 26 scenes, which can be reduced into the following plot: 
- The birth of the regal cub Simba, the ritual ceremony and its life in the kingdom

- The tragic death of the father lion Mufasa and the exile of the cub

- The life of the cub (and the young lion with the passing of time) in the wilderness

- The young lion meets its destined wife-to-be Nala and its introspection

- The young lion fights back and gets back its throne as the Lion King

The plot above, in analysis, closely resembles the monomyth, a universal story line which explains plot development (Jewett and Lawrence, 1977; W. Martin, 1986; in Rybacki \& Rybacki, 1991). The monomyth theory of plot claims that there is a common plot structure in all narratives in popular culture that contains three elements: a hero of royal birth -- the hero escapes death in childhood -- the hero goes on a journey and marries a princess or is given great honour. From this plot typology, we can develop the archetype of The Lion King as follows: the trial of the hero -- the awakening (baptism) of the hero -- the return of the hero -- the victory (rebirth) of the hero.

Falling into this universal mode, The Lion King thus inculcates in the audience several beliefs:

- the causal relationship of heroic birth and heroic victory. And hence, let's have faith in and rely on the hero;

- the antagonism of the legitimate and the illegitimate where the legitimate always wins or is awarded the honour. And hence, we should obey the legitimate (but who decides which is the legitimate?); and

- the hero, in order to achieve something (usually peace and happiness brought to the general populace, in addition to personal glory), has to go through a trial. And hence, it implies that people have to be patient and endure the hardship, if there is any, together.

\section{The Characters}

Here we will look into two characters of the text: the hero (the Lion King Simba) and the villain (Lion King's uncle Scar who stole away the throne) in order to elicit the themes of the story.

In Jungian model, the heroes have the following characteristics:

- they are good (in contrast to villains, who are evil; Simba is good-tempered, kind-hearted, loyal to friends and brave, etc);

- they are active (whereas many other characters are passive; Simba after introspection, actively goes back to Pride Land to fight for his "rightful" place);

- they often have helpers, assistance, and tutelary figures to teach them important things (Simba has Rafiki, who perform the ritual future king presentation ceremony, to enlighten him).

Apart from the story line, the physical portrayal of the two characters themselves already reveal their inner qualities. The mature Simba is young, energetic and calm-looking, with a clear and firm voice, and whenever he appears, except for in the fighting scenes and at night, the background is bright and sun rays shine everywhere. On the other hand, his uncle Scar (the name "scar" already tells of some bad things happened in the past, which now appears as a scar) has a scar just cross his left eye. He is skinny, with a low and secretive voice and a cunning look. Whenever he appears, the background is gray in colour And he always goes to the "shadowy" place where the bad hyenas live.

In Jungian psychology, the shadow is the dark side of the psyche, which we try to hide from consciousness. The basic function of the myth of the hero, a Jungian analyst Henderson (1968, in Berger, 1991) said, is to help individuals develop ego consciousness so that they can deal with the problems they will confront as they live their lives. Heroes are needed to help liberate people from regressive desires. In this regard, the hero archetype facilitates people to identify with the heroes, shedding undesirable traits, rendering the emergence of good and compliant citizens obeying the hegemonic reign.

\section{How do the Chinese Heroes Look Like in comparison?} Walker (1995) said:

From the treasure house of archetypal images are drawn the elements, the archetypal motifs, of mythology. Whether represented visually, dramatically, musically, or verbally, these motifs are usually found linked in a sequence, which we called a myth. Myths are thus not purely spontaneous products of the psyche; they are culturally elaborated. Over the centuries innumerable 
cultures have created a bewildering variety of myths out of the common human fund of the archetypal images of the collective unconscious. Mythology as a whole therefore constitutes a mirror for the collective unconscious, which is the common psychological basis for all human life.(4)

The above holds true when we examine the myths in Chinese communities. To substantiate this claim, let us review briefly two well-known myths.

1. Getting Rid of three Disasters

A man of noble descent called Zhou Chu is a local tyrant who is disliked by his fellow citizens (Royal birth). They secretly name Zhou, together with a flood dragon and a fierce white forehead tiger "Three Disasters". One day, people challenges his bravery to kill the other two disasters. Charged with pride, he kills the tiger and then goes straight to the sea for the flood dragon (the trial). After three days, Zhou does not show up, people think that the flood dragon and Zhou kill each other and they thus celebrate for the elimination of the three disasters. However, not long after, Zhou emerges from the sea after killing the flood dragon. When he discovers that people's hatred towards him is so intense, he suddenly realises his wrongs and decides to live a new life (Good character). He turns to a intellectual Lu Ji for help who gives him advice (Helper/assistant). Afterwards, Zhou turns a new leaf, becomes a dutiful son and loyal official in the government, benefiting all the people (He wins against himself -- the "shadows").

2. Hou Ji Benefits Farming

A concubine of a king called Jiang Yuan steps onto a huge foot print one day, and is inspired and gets pregnant. She gives birth to something like a meat ball (strange birth) and thinks that is an omen and intends to give it away (the trial). But when she tries to lay it down on the ditch, a huge bird comes near, with a wing spreading underneath it and the other covering it to give it warmth (helper /assistant). Jiang therefore thinks that the strange baby, Hou Ji must be a god and brings it back home. When Hou grows up, he is very talented at farming and teaches others the skills, benefiting the whole world. After he dies, rare and beautiful flowers appear all year long in the area around his burial place. Later, he resurrects from his death and becomes half-fish and half-human (Resurrection).

From the above, we can see that though the characters are different, the character traits and the story lines are more or less the same. In other words, the myths are culturally elaborated, but the social psyche seems universal. The implication of which will be discussed in the last section.

It's the Circle of Life...

"The Circle of Life", the theme song sang at the beginning of the animation, accompanied by the grand scene where all species of animals rush to the ledge of the Pride Rock to attend the ritual future king presentation ceremony, already depicts its importance. It is the circle of life that we all, human and animals have to respect. But what does it mean by the circle of life? What are its implications?

\section{Ecology}

[The Sunrise/Pouncing Scene]

Mufasa: Everything you see exists together, in a delicate balance. As king, you need to understand that balance, and respect all the creatures -- from the crawling ant to the leaping antelope.

Simba: But, dad, don't we eat antelope?

Mufasa: Yes, Simba, but let me explain. When we die, our bodies become the grass. And the antelopes eat the grass. And so we are all connected in the great Circle of Life.

Environmentalists may find this dialogue between Mufasa and Simba encouraging. We need to understand the balance (of the ecological system) and respect all the creatures. It seems that everything is equal in the end and there should hence be no query on the legitimacy of the lions eating the antelopes, the strong suppressing the week. It is just the circle of life. This line of thought actually legitimises the differences found in society, quieting those being suppressed.

\section{"Take Your Place" Motif}

In the animation, "take your place" motif appears quite often: Mufasa appears in the sky and tells Simba 


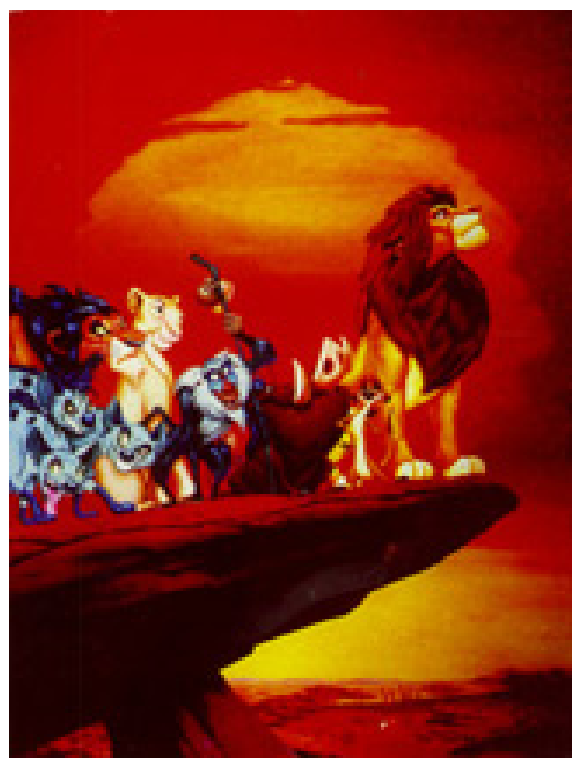

Figure 1: The Lion King (Roger Allers, Rob Minkoff, 1994)

that he must take his place in the Circle of Life, and Nala urges Simba to take his place as King. And when Simba is a child, he once steps onto his father's palmprint and it comes to him that he has some rather big shoes to fill, i.e. he suddenly realises his true position.

This "take your place" motif not only, actually, applies to Simba as a king. By extension, every one of us should take one's place in society. No complaints. Every one of us have his own role, whether it be big or small. And it is our responsibility to fulfill it. As Nala, Simba's friend and finally wife, tells Simba, "because it's your responsibility (emphasised)... and if you don't do something soon, everyone will starve." [Hammock Scene] Responsibility goes together with the place. Therefore every one of us has to act according to our roles.

\section{Fatalism}

Everything is destined. No one can escape from what is predestined for him. This theme is very apparent in the animation:

Mufasa: A king's time as ruler rises and falls like the sun. One day Simba, the sun will set on my time here -- and will rise with you as the new king. [The Sunrise/Pouncing Scene]

Zazu (a hornbill bird serves as the guardians of the regal cubs): Well sorry to bust your bubble, but you two turtle doves have no choice. It's a tradition... (talking about the marriage of Simba and Nala). [Water Hole Scene]

The ideology here is very clear. As a member of the general public, we have to accept what is preset for us. There is no bargain. Therefore we can hear Zazu says "Isn't it good to be on the top of the food chain?"...And So, There should be a Ruling Class.

\section{The Hierarchy}

So what do we know about the respect for the ecology, take one's place and fatalism? That is there exists a hierarchy in society. On top (of the food chain), those with power (When Simba tells Timon, his friend in exile life, that he is still the same guy, Timon, realising he is the king, says, "But with power!) are the ruling class. They have all the courage, intelligence, power, knowledge and every good quality that empower them to rule the society (as depicted in the story). And hence their legitimacy cannot be challenged.

Schwalm (1995) did a very in-depth analysis of the movie, exploring themes such as hierarchy and legitimacy, the role of nature, the importance of border, and religion, from the point of view of an America, relating the themes to the social and political events. Schwalm claims that the movie reinforces hierarchy, especially 
primogeniture. The message presented the traditional leaders as wise and benevolent, protecting the health and welfare of all the members of the community; while those outside the traditional group of leadership as illegitimate, and are inherently unfit to hold positions of authority.

\section{The Dominant Male}

The hegemony not only goes with the people in power politically, economically or socially. It also reinforces the male dominance phenomenon. In the animation, several phenomena reflect this aspect:

- Out of the fourteen characters, ten are male and four are female. Most of the male characters are very vocal while two of the female play only very subordinate roles

- Out of the 26 scenes, female characters only appear in eleven scenes and they mostly assume a bystander role;

Thompson and Serbinos (1995) analysed the gender roles in animated cartoons by comparing the communication/behaviour variables of the male and female characters. I adopt this method to analyse one of the scenes where there are both male and female interacting. I also simplify the variables to suit the purpose. The results are as below:

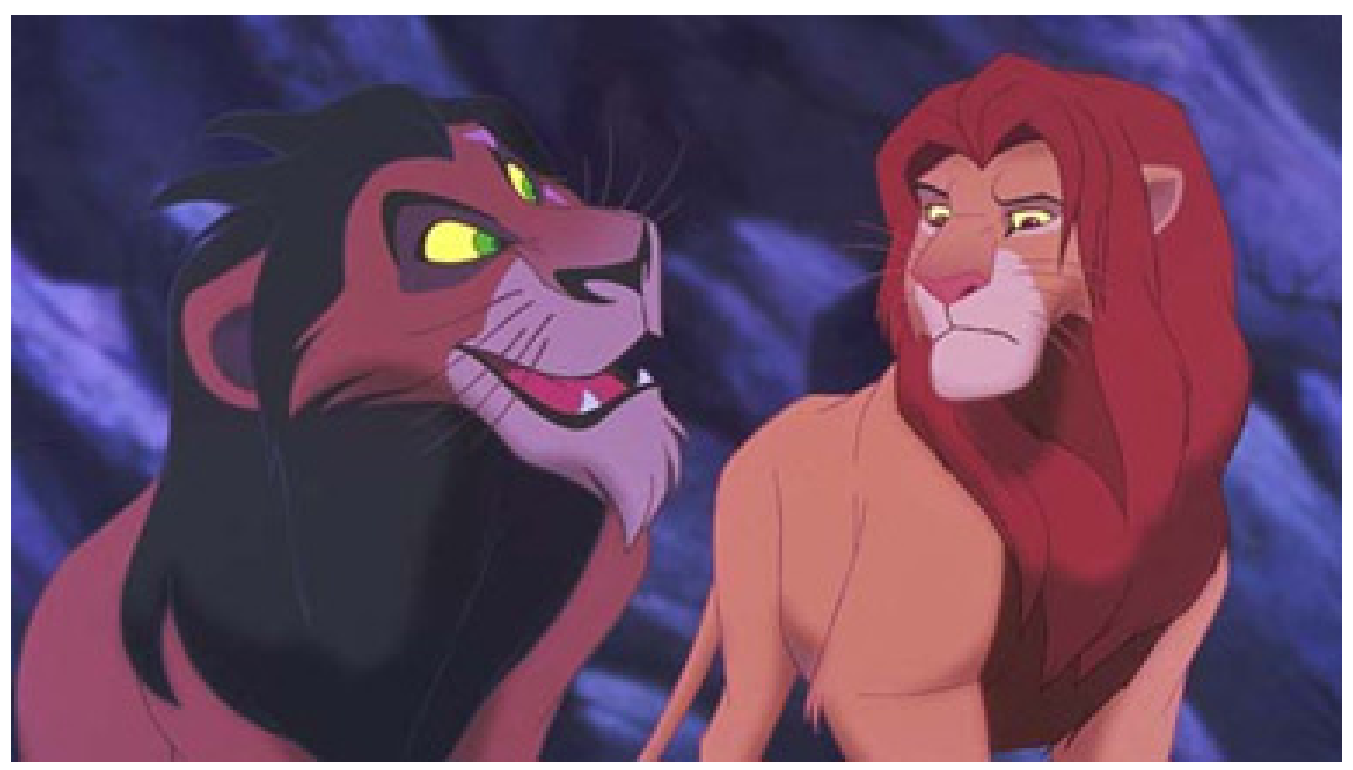

Figure 2: The Lion King (Roger Allers, Rob Minkoff, 1994)

Table 1 -- [Elephant Graveyard -- Hyena Scene] Male and female talk time/take the lead on various variables

\begin{tabular}{lll}
\hline Variables & Male & Female \\
Bragging & 5 & 2 \\
Ask for help & 0 & 2 \\
Take the lead for guidance & 1 & 0 \\
Showing bravery & 1 & 0 \\
\hline
\end{tabular}

The stereotypical traits for male (e.g. the protector) and female (e.g. the protected) are evident. In the ["Can you feel the love tonight" Scene], the female traits are even more prominent. Just take a look at Nala's posture, the expressions of her eyes and the seductive look and acts ("She gives him a tiny lick, resembling a kiss"), the female role is deduced to be object to be consumed by male. In many other scenes, it is males who make decision, who take the lead to fight and command. The male dominant society is further depicted and reinforced in the mind of the audience. 


\section{The Perspective of Hong Kong Chinese}

"Audience" has been a hit topic in media studies. However, according to Hacker et al (1991), quite a number of critics have challenged the use of "audience" as a theoretical construct. In fact, the passivity and activity of the audience have all along been a popular empirical study. Hacker et al (1991) concludes from their empirical study that "it is inadequate to assume that because television news is ideological, that its viewers are trapped in the same ideological schemata. Research has shown that audiences do not passively receive messages from news." (1991) Though the above research analysed a different genre (news), and that people seem to be more alert when watching/reading news, this papers holds the view that audience are not totally passive and receptive. What moves the audience are not just the plots, the emotions and the ideologies, it is these things that combine with the audience's experience, both personal, social and cultural etc that can really achieve effects. In this connection, I will argue that largely due to the cultural nurture, Hong Kong Chinese are very receptive to the ideologies projected in The Lion King.

The Confucius teaching very much emphasizes the five moral principles which legitimizes the hierarchical structure in society. The five principles are: King-official, Father-son, Elder-little brother, friends and Husband-wife. These are arranged in descending order of importance pair-wise and between pairs. The Chinese society, as a collective community, is basically a very structured entity, with various roles defined for various strata to play. And within the family, the eldest sons of the eldest son is the most treasured. They are given the best treatment, and a large portion, if not most, of the inheritance. This tradition still exists in Hong Kong especially among the local villagers. On the male dominance phenomenon it is the Chinese culture that a virtuous woman has to, literally, "follow" (rely on and listen to) three men, i.e. when she is a child, she has to follow her father; as a married woman, her husband; and when she is old, her son. And there are a lot more rituals and customs that a Chinese woman has to follow. These androcentric thoughts abound everywhere, in society structure, in familial situation, and in the textbooks alike. In my other study attempting to deconstruct the popular songs in Hong Kong during the 50/60's and 90's in order to extract the underlying androcentric thoughts which devalue, if not victimise, females, it is found that the hegemony that males are the dominant force in society can easily be felt, and the cultural ideals that women are to be submissive, possessions of men, and play a secondary role in society are clearly communicated.

It is therefore argued that the social psyche of the Hong Kong Chinese is very much alike those depicted in The Lion King, therefore the people in question, if not receptive to, do not find the messages the animation projects offensive. And actually because of this, the hegemony may even be reinforced further without people knowing the effect.

\section{Conclusion}

In this paper, I argue that The Lion King is not merely a light entertainment. It is filled with ideologies of power and male dominance hegemony, legitimising the position and privileges of the existing authority and of men. The general populace and women are persuaded to "take their place" as a secondary role in society, to listen to and serve those in power and men willingly and without complaint. They are also taught to rely on and have faith in the former, and to endure the hardship and be patient if things go wrong, since those in power and the men, equipped with the intelligence, power and luck are destined to rule the world and be the winners in the end.

In addition, the fact that the animation was so well received in Hong Kong is partly due to the aesthetic appeal, but mainly because the social psyche resembles those themes and ideologies projected in the film. Adding to the fact that the theatrical environment which demands intense attention of the viewers, the ideologies of the animation can be easily integrated into the viewers mind. As Greene (1995) analysed in terms of the Jungian model:

People line up outside of the theatre to purchase ingress. Once inside, all members of the audience become equal in their role of participating in the mysteries of which they are about to behold. The group's sharing of the moment with one another in the darkened room adds to the uniqueness of the experience. By participating.... context is created... The content of the myth coupled with the structure of the medium lend itself to facilitating such an experience for the viewer." (on the Internet)

On the theoretical side, the archetype deduced from The Lion King startlingly resembles those found in 
Chinese fables, myths and religions. The analysis (i.e. similarity in the archetype of West-East cultures) further confirms an important fact of the Jungian Theory that although cultures are abundant and vary, there are some universal themes and archetypes. These not only can be found in literature, such as novels and poems, but also in the film (and here animation movie) genre as well.

\section{References}

\section{Bibliography}

Beebe, J. (1994). Schindler's List. Film Commentary. San Francesco Jung Institute Library Journal: V12(4), 1994 (pp79-80).

Berger, A.A. (1995). Cultural Criticism: A Primer of Key Concepts. California: SAGE.

Ebert, R. (1994). The Lion King. Chicago Sun-Time. 6/24/1994.http://www.suntimes.com/ebert/ebert_reviews/1994/06/92

Greene, M. (1995). The Myth of the Redeemer in Contemporary Cinema

http://www.cgjung.com/films/redeem.html.

Hacker, K. L.; Coste, T. G.; \& Kamm, D. F. (1991). Oppositional readings of network television news: viewer deconstruction. Discourse 85 Society. (183-202) London: Sage.

Hart, R. (1990). Ideological Analysis. In Modern Rhetorical Criticism, pp381-422. Glenview Illinois: Scott, Foresman/Little.

Hinson, H. (1994). The Lion King. Washington Post. 6/24/1994

http://washingtonpost.com/wp-srv/style/longterm/review96/lionkinghin.htm.

Neufeld, B. (1996). Anthropomorphism in "The Lion Kong".

http://www.gate.net/ bneufeld/lionking.html.

Robertson, R. (1995). Jungian Archetypes -- Jung, Goedel, and the History of Archetypes. http://www.cgjung.com/articles/rr

Ryback \& Rybacki (1991). Communication Criticism: Approaches and Genres. California: Wadsworth Publishing.

Schleifer, R. (1992). Institutions of Cultural Studies.

http://www.tornade.ere.umontreal.cal guedon/Surfaces/vol2/schleife.html

Schwalm, K. (1995). Patriarchy in the Pride Land -- a Cultural Analysis of The Lion King.

http: //www.gc.maricopa.edu/ schwalm/lionkimg.html

Sillars, M. (1991). Narrative analysis. in Messages, Meanings and Culture: Approaches to Communication Criticism. Pp149-170. NY: Harper Collins, 1991.

Thompson, T. L. \& Zerbinos, E. (1995). Gender roles in animated cartoons: Has the picture changed in 20 years? Sex Roles, V32 (9/10), 1995, 651-673.

Walker, S.F. (1995). Jung and the Jungians on Myth. NY: Garland.

Williams, D. (1997). Notes on Character, Dreams, Filmmaking, and Fiction. http://www.cgjung.com/films/dwnotes.html

Young-Eisendrath, P. (1996). Struggling with Jung: the Value of Uncertainty. http://www.cgjung.com/articles/pollyrtr.html.

\section{Author Information}

Vicky WONG received her M.A. from the School of Oriental and African Studies, University of London and Hong Kong Baptist University. She developed her interest in film perception and communications while working at the Hong Kong International Film Festival secretariat as a translator. 